\title{
Proteasome modulator 9 and macrovascular pathology of T2D
}

Claudia Gragnoli, 1,3

\begin{abstract}
Aims: Coronary artery disease (CAD) and stroke share a major linkage at the chromosome 12q24 locus. The same chromosome region entails at least a major risk gene for type 2 diabetes (T2D) within NIDDM2, the non-insulindependent-diabetes 2 locus. The gene of Proteasome Modulator 9 (PSMD9) lies in the NIDDM2 region and is implicated in diabetes in mice. PSMD9 mutations rarely cause T2D and common variants are linked to both lateonset T2D and maturity-onset-diabetes of the young (MODY3). In this study, we aimed at determining whether PSMD9 is linked to macrovascular pathology of T2D.

Methods and Results: In our 200 T2D families from Italy, we characterized the clinical phenotype of macrovascular pathology by defining the subjects for presence or absence of CAD, stroke and/or transitory ischemic attacks (TIA), plaques of the large arterial vessels (macro-vasculopathy) and arterial angioplasty performance. We then screened 200 T2D siblings/families for PSMD9 +nt460A/G, +nt437C/T and exon E197G A/G single nucleotide polymorphisms (SNPs) and performed a non-parametric linkage study to test for linkage for coronary artery disease, stroke/TIA, macro-vasculopathy and macrovascular pathology of T2D. We performed 1,000 replicates to test the power of our significant results. Our results show a consistent significant LOD score in linkage with all the above-mentioned phenotypes. Our 1000 simulation analyses, performed for each single test, confirm that the results are not due to random chance.
\end{abstract}

Conclusions: In summary, the PSMD9 IVS3+nt460A/G, +nt437C/T and exon E197G A/G SNPs are linked to CAD, stroke/TIA and macrovascular pathology of T2D in Italians.

\section{Introduction}

Type 2 diabetes (T2D) has long-term complications, both microvascular and macrovascular. The microvascular complications entail the diabetic retinopathy, diabetic neuropathy and diabetic nephropathy. The macrovascular complications are represented by coronary artery disease (CAD), stroke, transitory ischemic attacks (TIA), and atherosclerotic plaques in major arterial vessels. The history of arterial angioplasty in a patient also implicates the presence of macro-vasculopathy. Given the high impact of macrovascular pathology on life quality and life expectancy, it is quite important to identify risk genes contributing to such polygenic and complex phenotype.

\footnotetext{
Correspondence: claudia.gragnoli@gmail.com

'Laboratory of Molecular Genetics of Complex and Monogenic Disorders,

Department of Medicine and Cellular \& Molecular Physiology and

Biostatistics, Penn State University and M. S. Hershey Medical Center,

Hershey, PA, USA

Full list of author information is available at the end of the article
}

Recently, a study reported a significant linkage to coronary artery disease (CAD) [1], myocardial infarction [1,2], stroke [3] to the chromosomal locus 12q24, within the NIDDM2 locus in which PSMD9 is located.

PSMD9 unique mutations rarely cause T2D [4]. We identified a significant linkage of PSMD9 common single nucleotide polymorphism (SNPs) to late-onset T2D, via recessive/additive model [5], as well as to early-onset T2D/MODY3 via additive model in Italians families [6]. The PSMD9 role in beta cell dysfunction and T2D in mice is known [7].

The aim of the present study was to determine whether the $I V S 3+n t 460 A / G,+n t 437 C / T$ and exon E197G A/G T2D risk SNPs of PSMD9 cause evidence for linkage with other T2D-associated phenotypes such as CAD, stroke/TIA, vasculopathy and macrovascular pathology of T2D in Italians.

\section{Ciomed Central}

() 2011 Gragnoli; licensee BioMed Central Ltd. This is an Open Access article distributed under the terms of the Creative Commons Attribution License (http://creativecommons.org/licenses/by/2.0), which permits unrestricted use, distribution, and reproduction in any medium, provided the original work is properly cited. 


\section{Methods}

\section{Ethical Statement}

The subjects were all recruited from Rome, Italy following the Helsinki declaration guidelines. Subjects gave written informed consent and the Penn State College of Medicine Ethical Committee approved the study.

\section{Families}

We previously recruited 200 Italian T2D affected siblings and families with both T2D affected and unaffected members [8]. We excluded all families with identical twins, both parents affected and genetic admixture with no Italians. We confirmed that the families were for at least three generations Italians. In addition, the Italians are suitable for genetic studies as they are a homogeneous population from a geographically restricted peninsula.

\section{Clinical Phenotyping}

We characterized the family subjects with T2D and without T2D for presence/absence of coronary arterial disease (CAD: angina or myocardial infarction/coronary angioplasty/presence of pathological Q waves on the electrocardiogram), cerebrovascular events (stroke/transitory ischemic attacks), vasculopathy (plaque(s) on carotid arteries/lower extremities arteries, and/or arterial angioplasty), and macrovascular pathology (vasculopathy and/or CAD and/or cerebrovascular events). Phenotypes of macrovascular pathology are described as unknown if diagnosis is unclear or data are lacking; subjects are described as affected if they carry the phenotype under study and as unaffected if they do not have the phenotype. In our 200 Italian families, for each phenotype, data are less than $100 \%$.

\section{Sequencing}

We sequenced the PSMD9 IVS3+nt460/+nt437/E197G SNPs in all family members. We directly sequenced the PCR products, status post-purification via EXOSAP-IT on an automated ABI 3730 Sequencer.

\section{Statistical Analysis}

We tested in the 200 Italian families for linkage of the PSMD9 SNPs with all described phenotypes. The three SNPs studied are in linkage disequilibrium as previously shown [4]. The map distance between each SNP pair given for the linkage analysis was $0.1 \mathrm{cM}$. We performed our statistical analysis using the latest version of Merlin software [9] and the allelic information of a total of 200 genotyped families. Merlin analyzed all the informative families within this dataset. Non-parametric linkage analysis was performed for the IVS3+nt460A/G, $+n t 437 C / T$ and exon E197G A/G SNPs. Each phenotype was tested independently using for the above-mentioned three
SNPs the same map distance (cm 139.1, 139.2, 139.3 on the same chromosome, respectively). Merlin calculated the linkage score for each of these SNPs in linkage disequilibrium as a single locus, as it reported only one LOD score per statistical test, which implies that Merlin considered the SNPs located on a single locus.

All results are reported as LOD scores calculated by Merlin. For each test performed for each specific phenotype, to exclude false positive results, we calculated the empirical P-value in 1,000 replicates of simulations by using the gene dropping method: this analysis replaces real data with simulated data, while maintaining the pedigree structure, allele frequencies and recombination fraction. These datasets are generated under the null hypothesis of no linkage. The empirical P-value for each phenotype-specific test was calculated based on the Pvalue corresponding to the single LOD score given by Merlin for the three SNPs analysis at one locus and using the same map distance of the real analysis. Further, the outcome of the simulations was calculated taking in consideration how many times in 1,000 replicates there was a P-value equal to or smaller than the $\mathrm{P}$-value of the real analysis.

\section{Results}

The LOD scores of the non-parametric linkage analysis, performed for the various phenotypes, are reported, jointly for the three tested SNPs, with their corresponding P-value as well as with the results of the 1000 simulations (Table 1). Linkage is shown significantly for the CAD phenotype, the stroke/TIA phenotype and the macrovascular pathology phenotype and with a less significant empirical $\mathrm{P}$-value with the vasculopathy phenotype.

\section{Discussion}

Our study shows that the PSMD9 IVS3+nt460A/G, $+n t 437 C / T$ and exon $E 197 G$ A/G SNPs studied are in linkage with CAD, cerebrovascular events, vasculopathy, and macrovascular pathology. The simulation analyses rule out false results for the linkage to CAD, stroke and macrovascular pathology at the significance level of at least $\alpha=0.005$, however the significance level of the vasculopathy linkage is only at $\alpha=0.053$. Thus, PSMD9 or any of its variants contribute to linkage of the reported phenotypes.

Of note, the potential contribution of intronic variants to complex disorders such as atherosclerosis and/or major cardiovascular events is widely accepted.

However, we think it is important to take in consideration that the linkage signal detected for the macrovascular pathology phenotypes in our study may indeed reflect the underlying linkage for T2D [5]. In fact, we recognize that it is difficult to disentangle associated 
Table 1 Non-parametric Linkage Analysis of Various Phenotypes of the 200 Italian Families by Merlin software

\begin{tabular}{lccccc}
\hline Phenotype & Prevalence & Families & Lod Score & P-value & Empirical P-value \\
\hline CAD & $28.20 \%$ & 15 & 1.39 & 0.006 & 0.005 \\
Stroke & $14.80 \%$ & 5 & 1.04 & 0.014 & 0.002 \\
Vasculopathy & $53.80 \%$ & 48 & 0.64 & 0.040 & 0.053 \\
Macrovascular Pathology & $70.10 \%$ & 78 & 2.21 & 0.0007 & 0.002 \\
\hline
\end{tabular}

Prevalence $=$ phenotype prevalence among the family subjects studied; Families = families number analyzed; Lod score = derived from the non-parametric linkage analysis by Merlin; Empirical P-value = derived from 1000 replicates by using the gene dropping method; CAD = coronary artery disease; Vasculopathy = based on the presence of plaques and/or angioplasty of carotid arteries, coronary arteries, lower extremities arteries; Macrovascular Pathology = based on the presence of CAD and/or Stroke/TIA and/or Vasculopathy.

complex phenotypes in a family-based linkage study targeted at one phenotype only at a time. Despite the necessity to raise concerns about the potential implications of the statistical data, we think that it is possible that a gene responsible for $\mathrm{T} 2 \mathrm{D}$ is also contributing to macrovascular disease. This interpretation is based on the fact that the two complex phenotypes are strongly associated as well as that the same locus is linked in multiple studies to T2D $[10,11]$ and macrovascular disease $[3,1]$.

PSMD9 gene has the potential of having pleiotropic effects. Recently, we published the contribution of the same gene to T2D-nephropathy [12], which is a microvascular complication of T2D and is linked to the $12 \mathrm{q} 24$ locus [13].

Our results should be replicated in different T2D ethnic groups and are of relevance to the T2D families as well as to the families with macrovascular pathology without T2D carrying linkage in the chromosome 12q24 locus, which may be explained by the PSMD9 variants, at least partially. This locus in fact was reported as linked to macrovascular pathology in other populations [1-3]. In addition, we hereby prove the strength and validity of the SNP-based linkage approach in identifying genes in complex disorders. Microsatellite used mostly in the past as markers for linkage studies in polygenic diseases should be revisited, as they may have disempowered the linkage strategy. Also, family-based linkage studies are stronger in their statistical power compared to association studies. Our Italian family dataset is ethnically homogenous, thus it allows significant results to be revealed. The mechanism by which the PSMD9 protein may contribute to the macrovascular pathology is unknown at the present time.

Lifetime expectancy is highly affected by the presence of atherosclerosis and macrovascular pathology, thus the impact of the identification of a risk gene to macrovascular pathology is inestimable.

\section{Acknowledgements}

Special thanks go to the Molecular Biology staff of Bios Biotech MultiDiagnostic Health Center (Rome, Italy), which provided technical support for this study.
This work was supported by Penn State College of Medicine and by Bios Biotech Multi-Diagnostic Health Center (Rome, Italy).

\section{Author details}

'Laboratory of Molecular Genetics of Complex and Monogenic Disorders, Department of Medicine and Cellular \& Molecular Physiology and Biostatistics, Penn State University and M. S. Hershey Medical Center, Hershey, PA, USA. 'Center for Biotechnology and Department of Biology, Temple University's College of Science \& Technology, Philadelphia, PA, USA ${ }^{3}$ Molecular Biology Laboratory, Bios Biotech Multi-Diagnostic Health Center, Rome, Italy.

\section{Authors' contributions}

CG conceived and designed the study, collected the clinical information, performed the statistical analysis and drafted the manuscript.

\section{Conflict of interests}

The authors declare that they have no competing interests.

Received: 14 February 2011 Accepted: 17 April 2011

Published: 17 April 2011

\section{References}

1. Zintzaras E, Kitsios G: Identification of chromosomal regions linked to premature myocardial infarction: a meta-analysis of whole-genome searches. J Hum Genet 2006, 51:1015.

2. Gudbjartsson DF, Bjornsdottir US, Halapi E, Helgadottir A, Sulem P, Jonsdottir GM, Thorleifsson G, Helgadottir H, Steinthorsdottir V, Stefansson H, Williams C, Hui J, Beilby J, Warrington NM, James A, Palmer LJ, Koppelman GH, Heinzmann A, Krueger M, Boezen HM, Wheatley A, Altmuller J, Shin HD, Uh ST, Cheong HS, Jonsdottir B, Gislason D, Park CS, Rasmussen LM, Porsbjerg C, Hansen JW, Backer V, Werge T, Janson C, Jonsson UB, Ng MC, Chan J, So WY, Ma R, Shah SH, Granger CB, Quyyumi AA, Levey Al, Vaccarino V, Reilly MP, Rader DJ, Williams MJ, van Rij AM, Jones GT, Trabetti E, Malerba G, Pignatti PF, Boner A, Pescollderungg L, Girelli D, Olivieri O, Martinelli N, Ludviksson BR, Ludviksdottir D, Eyjolfsson Gl, Arnar D, Thorgeirsson G, Deichmann K, Thompson PJ, Wjst M, Hall IP, Postma DS, Gislason T, Gulcher J, Kong A, Jonsdottir I, Thorsteinsdottir U, Stefansson K: Sequence variants affecting eosinophil numbers associate with asthma and myocardial infarction. Nat Genet 2009, 41:342.

3. Sherva R, Miller MB, Pankow JS, Hunt SC, Boerwinkle E, Mosley TH, Weder AB, Curb JD, Luke A, Morrison AC, Fornage M, Arnett DK: A wholegenome scan for stroke or myocardial infarction in family blood pressure program families. Stroke 2008, 39:1115.

4. Gragnoli C, Cronsell J: PSMD9 gene variants within NIDDM2 may rarely contribute to type 2 diabetes. J Cell Physiol 2007, 212:568.

5. Gragnoli C: PSMD9 gene in the NIDDM2 locus is linked to type 2 diabetes in Italians. J Cell Physiol 2010, 222:265.

6. Gragnoli C: PSMD9 is linked to MODY3. J Cell Physiol 2010, 223:1.

7. Thomas MKYK, Tenser MS, Wong GG, Habener JF: Bridge-1, a novel PDZdomain coactivator of E2A-mediated regulation of insulin gene transcription. Mol Cell Biol 1999, 19:8492.

8. Milord E, Gragnoli C: NEUROG3 variants and type 2 diabetes in Italians. Minerva Med 2006, 97:373.

9. Abecasis GR, Cherny SS, Cookson WO, Cardon LR: Merlin-rapid analysis of dense genetic maps using sparse gene flow trees. Nat Genet 2002, 30:97. 
10. Mahtani MM, Widen E, Lehto M, Thomas J, McCarthy M, Brayer J, Bryant B, Chan G, Daly M, Forsblom C, Kanninen T, Kirby A, Kruglyak L, Munnelly K, Parkkonen M, Reeve-Daly MP, Weaver A, Brettin T, Duyk G, Lander ES, Groop LC: Mapping of a gene for type 2 diabetes associated with an insulin secretion defect by a genome scan in Finnish families. Nat Genet 1996, 14:90.

11. Wiltshire SFT, Groves CJ, Levy JC, Hitman GA, Sampson M, Walker M, Menzel S, Hattersley AT, Cardon LRMM: Evidence from a large U.K. family collection that genes influencing age of onset of type 2 diabetes map to chromosome $12 p$ and to the MODY3/NIDDM2 locus on 12q24. Diabetes 2004, 53:855.

12. Gragnoli C: T2D-Nephropathy Linkage within 12q24 Locus Diabetes. Res Clin Pract 2011.

13. Bowden DW, Sale M, Howard TD, Qadri A, Spray BJ, Rothschild CB, Akots G, Rich SS, Freedman BI: Linkage of genetic markers on human chromosomes 20 and 12 to NIDDM in Caucasian sib pairs with a history of diabetic nephropathy. Diabetes 1997, 46:882.

doi:10.1186/1475-2840-10-32

Cite this article as: Gragnoli: Proteasome modulator 9 and

macrovascular pathology of T2D. Cardiovascular Diabetology 2011 10:32.

\section{Submit your next manuscript to BioMed Central} and take full advantage of:

- Convenient online submission

- Thorough peer review

- No space constraints or color figure charges

- Immediate publication on acceptance

- Inclusion in PubMed, CAS, Scopus and Google Scholar

- Research which is freely available for redistribution

Submit your manuscript at www.biomedcentral.com/submit 